\title{
Desenvolvimento de PVC Reforçado com Resíduos de Pinus para Substituir Madeira Convencional em Diversas Aplicações
}

\author{
Antonio Rodolfo Jr. \\ Braskem S/A \\ Vanderley M. John \\ Departamento de Engenharia de Construção Civil e Urbana, EPUSP
}

\begin{abstract}
Resumo: Este trabalho avalia a viabilidade técnica da obtenção de compósitos lignocelulósicos de PVC, utilizando-se resíduo de Pinus elliottii e Pinus taeda como carga reforçativa. Foi desenvolvido um processo simples e economicamente viável de tratamento de resíduos industriais desta madeira, processo este baseado na secagem e revestimento das partículas com lubrificantes funcionais e agentes de acoplamento utilizados como aditivos na indústria do PVC, bem como no uso de equipamentos tradicionais da indústria de processamento deste termoplástico. Foram avaliados os efeitos da incorporação da farinha de madeira em concentrações variáveis e do tipo de agente de tratamento superficial utilizado na processabilidade do composto de PVC, bem como em propriedades finais do compósito. Os resultados mostram que o desenvolvimento deste tipo de material compósito é uma alternativa viável para a substituição da madeira convencional em diversas aplicações.
\end{abstract}

Palavras-chave: PVC, poli(cloreto de vinila), farinha de madeira, reforço lignocelulósico, compósito PVC/madeira.

\section{Development of PVC/wood composites for the replacement of conventional wood products}

Abstract: This work evaluates the technical viability of lignocellulosic vinyl composites, using residues of Pinus elliottii and Pinus taeda as the reinforcement fiber. A simple and economically viable process for the treatment of these industrial residues was developed. The process includes sieving, drying and treating the wood particles. Treatment is made with functional lubricants and coupling agents used as additives in the PVC industry. Extrusion was performed using traditional equipment available in the Brazilian PVC processing industry. The effect on the processability of the variable concentrations of the residues incorporated and the type of agent used for the treatment had been evaluated, as well as in the final properties of the composite. The results show that the development of this kind of composite material is a viable alternative for the substitution of conventional wood in diverse applications.

Keywords: PVC, poly(vinyl chloride), wood flour, PVC/wood composite.

\section{Introdução}

O uso de madeira como carga reforçativa em polímeros é uma área do conhecimento e da economia mundial que tem se desenvolvido intensamente nos últimos anos. Dados recentes dão conta de que, somente nos EUA, cerca de 400 mil t de polímeros carregados com reforços lignocelulósicos diversos foram utilizados no ano $2002^{[1]}$. Este mercado também tem apresentado crescimento vigoroso nos últimos anos: $60 \%$ de crescimento anual nos EUA para aplicações ligadas à construção civil[ ${ }^{[1-3]}$. Deste total, cerca de $36.000 \mathrm{t}$, ou $9 \%$, corresponde a compósitos lignocelulósicos de poli(cloreto de vinila) (PVC). Grande parte do crescimento da demanda desta nova classe de materiais deve-se à eliminação voluntária iniciada em 2003 nos EUA de produtos em madeira tratados com preservativos baseados em Cromo-Cobre-Arsênio - $\mathrm{CCA}^{[4]}$. A disposição de resíduos de madeira tratada com estes preservativos traz grande preocupação devido à possibilidade de lixiviação de metais tóxicos para o ambiente, ou mesmo emissões para a atmosfera no caso de combustão ${ }^{[5]}$. Para o Brasil, infelizmente, não existem dados sobre esta demanda, tendo em vista principalmente que as aplicações são ainda bastante emergentes.

A aplicação de reforços lignocelulósicos em resinas do tipo fenol formaldeído é comum desde o início do século $\mathrm{XX}^{[1]}$. No mercado de decking estes polímeros carregados com reforço lignocelulósico competem principalmente com a madeira tratada sob pressão. Apesar de ser um assunto bastante difundido no meio industrial, com uma série de empresas fornecendo produtos comerciais baseados em diferentes tecnologias de composição do PVC com resíduos de madeira industrializados ${ }^{[6]}$, um levantamento realizado pelos autores ${ }^{[7]}$ mostrou que poucas publicações científicas, 
específicas para este polímero, avaliam a utilização de resíduos de madeira como carga reforçativa do PVC rígido. Mesmo a literatura existente concentra trabalhos ligados a poucos pesquisadores e centros de pesquisa.

Apesar do fato de que o PVC é o terceiro termoplástico em termos de consumo mundial, totalizando $20 \%$ das mais de 140 milhões de toneladas consumidas em $2003^{[8]}$, foram apresentados somente quatro trabalhos sobre compósitos lignocelulósicos de PVC de um total de 21 trabalhos sobre o tema compósitos lignocelulósicos poliméricos na edição de 2003 na ANTEC - Annual Technical Conference, um dos principais eventos técnico-científicos da comunidade de polímeros realizado anualmente pela SPE - Society of Plastics Engineers dos EUA. Ao mesmo tempo, o tema nanocompósitos envolveu a apresentação de 61 trabalhos nesta mesma edição da conferência. Pode-se dizer que a participação do PVC foi insignificante se comparada com a demanda per capita de PVC observada neste país, superior a $21 \mathrm{~kg} / \mathrm{hab}$ ano ${ }^{[8]}$, comparável à demanda per capita total de termoplásticos no Brasil, que é de cerca de $23 \mathrm{~kg} / \mathrm{hab} / \mathrm{ano}$.

O interesse da comunidade industrial por compósitos de polímeros com reforços lignocelulósicos supera em muito o interesse por nanocompósitos poliméricos, outra área de pesquisa que tem despertado muito interesse da comunidade acadêmica no momento. Esta constatação pelo lado industrial foi realizada por um dos autores em visita realizada no ano de 2004 à maior feira mundial de tecnologia do plástico, a K 2004, feira esta realizada a cada três anos na cidade alemã de Düsseldorf.

Uma pesquisa realizada pelos autores ${ }^{[7]}$ nos portais $I S I W e b$ of Knowledge e Derwent Innovations Index (www. isiknowledge.com) para artigos e patentes publicados entre 1970 e 2005, utilizando-se das palavras-chave "polymer AND nanocomposite" em comparação com as chaves "(polymer + plastic) AND wood AND (composite OR compound)" e "pvc AND wood AND (composite OR compound)", mostra uma grande discrepância em termos de importância relativa da comunidade acadêmica. Para o caso dos artigos científicos, enquanto que o tema "nanocompósitos" retorna 1.281 artigos para o período pesquisado, o tema "polímero/madeira" retorna somente 311 artigos, e o tema "PVC/madeira" menos ainda: 30 artigos. Novamente os resultados são pouco significantes, principalmente ao levar-se em consideração que compósitos polímero/madeira são uma realidade no mercado norte-americano há pelo menos cinco anos.

Interessante notar que o refinamento desta pesquisa para o período entre aos anos 2000 e 2005 retorna resultados pouco diferentes: 1.281 artigos sobre o tema "nanocompósitos" (o mesmo valor anterior por ser nova área do conhecimento), 296 artigos sobre o tema "polímero/madeira" e os mesmos 30 artigos sobre o tema "PVC/madeira". Nota-se que o tema "PVC/madeira" é tão novo quanto o tema "nanocompósitos", porém tem recebido muito menos atenção da comunidade acadêmica, apesar da presença desta nova classe de materiais em produtos disponíveis em mercados tais como o norteamericano.
A situação em patentes traz resultados mais significativos para os compósitos lignocelulósicos. O tema "polímero/madeira" retorna 2.946 patentes entre 1970 e 2005, sendo 308 patentes sobre o tema "PVC/madeira". O tema nanocompósitos, ainda bastante emergente, retorna somente 270 patentes, sendo 252 delas publicadas após o ano 2000.

A experiência brasileira com polímeros reforçados com reforços lignocelulósicos é limitada, conforme evidencia pesquisa bibliográfica preliminar ${ }^{[7]}$. Pode-se afirmar que este tema é desenvolvido no Brasil somente em alguns poucos centros de pesquisa, dentre as quais pode-se citar a Embrapa - São $\operatorname{Carlos}^{[9-12]}$, o Departamento de Engenharia de Materiais da Universidade Federal de São Carlos ${ }^{[13-17]}$, o Departamento de Engenharia de Materiais da Universidade Federal de Campina Grande ${ }^{[18,19]}$, o Instituto Militar de Engenharia $^{[20]}$, o Instituto de Macromoléculas Prof ${ }^{a}$ Eloísa Mano da Universidade Federal do Rio de Janeiro ${ }^{[21]}$, a Universidade São Francisco ${ }^{[22]}$ e a Faculdade de Engenharia Industrial ${ }^{[23,24]}$.

Novos materiais compósitos que trazem benefícios tanto ambientais quanto econômicos estão sendo desenvolvidos pela indústria para aplicação nas áreas da construção civil, moveleira, automobilística e de embalagens. Enquanto que a utilização de reforços lignocelulósicos em resinas termofixas remete à origem da indústria de polímeros tais como as resinas fenólicas, o uso de termoplásticos reforçados com estes reforços de origem natural somente recentemente passou a ter aceitação no mercado. Apesar de produtos em polipropileno carregado com reforços lignocelulósicos serem utilizados no interior de automóveis desde a década de $1970^{[25]}$, em placas conhecidas no Brasil pela denominação comercial Woodstock ${ }^{\circledR}$, é somente a partir da segunda metade da década de 1990 que o interesse da comunidade acadêmica e industrial sobre compósitos termoplásticos carregados com reforços lignocelulósicos ganha algum destaque, possivelmente pela elevada pressão de custos crescentes dos materiais plásticos.

Entretanto, o interesse ocorre no sentido da utilização de reforços lignocelulósicos em matrizes termoplásticas, ao contrário da idéia original da aplicação automobilística supracitada, na qual as partículas de madeira são somente enchimento do material plástico (carga), objetivando redução de custo. A obtenção de compósitos, no sentido estrito da palavra, depende do entendimento das interações na interface entre a matriz polimérica e o reforço lignocelulósico, bem como do desenvolvimento de técnicas de processamento que garantam a extração da umidade remanescente na carga reforçativa e a correta dispersão e homogeneização das fibras ou partículas na matriz polimérica.

Diversas tecnologias estão sendo desenvolvidas, utilizando-se de diferentes matrizes poliméricas e diferentes tipos de reforços lignocelulósicos. O potencial de desenvolvimento de novos materiais compósitos combinando-se matrizes termoplásticas e cargas reforçativas de origem lignocelulósicas é imenso. A idéia básica é sempre combinar dois materiais, buscando-se sinergia de propriedades. $\mathrm{O}$ uso de polímeros sintéticos, sempre dependentes do petróleo, com fibras ou partículas provenientes de recursos naturais 
renováveis, permite a obtenção de materiais com custos competitivos e menor dependência das reservas de petróleo.

As principais vantagens da utilização de reforços lignocelulósicos em polímeros podem ser resumidas em baixa densidade, baixa abrasividade, possibilidade de incorporação de elevados teores resultando em elevada rigidez, manutenção da reciclabilidade, biodegradabilidade, ampla variedade de cargas reforçativas disponíveis em todo o mundo, oferta de trabalho no campo em uma economia rural não mais dependente somente da agricultura para alimentação, baixo consumo de energia e baixo custo. Grande parte destas vantagens não são ignoradas em segmentos da economia tais como na construção civil e na indústria automobilística, somente para citar dois exemplos.

Entretanto, esta tecnologia emergente possui suas limitações. Talvez a principal delas seja a impossibilidade de processamento de polímeros carregados com reforços lignocelulósicos em temperaturas demasiadamente elevadas, por exemplo acima de $200^{\circ} \mathrm{C}$ por longos períodos, devido à susceptibilidade da carga lignocelulósica sofrer degradação térmica. Esta limitação define os tipos de termoplásticos que podem ser utilizados como matrizes poliméricas no sistema: termoplásticos ditos commodities tais como o PVC, os polietilenos (PE), o polipropileno (PP) e o poliestireno (PS), dentre outros, polímeros estes processáveis a temperaturas compatíveis com os limites impostos pelo reforço lignocelulósico. Entretanto, não se pode ignorar que estes quatro termoplásticos correspondem a mais de $70 \%$ de todo o plástico consumido anualmente no mundo e, conseqüentemente, o uso das reforços lignocelulósicos nestes polímeros supera em muito qualquer possibilidade de uso em outros plásticos mais nobres ${ }^{[1]}$.

Uma segunda limitação é a elevada capacidade de absorção de umidade do reforço lignocelulósico, a qual resulta em inchamento das partículas e perda de estabilidade dimensional. Esta capacidade de absorção de umidade pode ser limitada através do correto encapsulamento das partículas pela matriz polimérica, sendo que este encapsulamento é mais efetivo quanto melhor a capacidade de adesão da matriz polimérica à superfície das mesmas. A elevada capacidade de absorção de umidade também traz dificuldades no processamento do compósito, tornando necessária a secagem prévia do reforço lignocelulósico e uma série de cuidados para a manutenção dos baixos níveis de umidade conseguidos com esta operação, tais como o tratamento das partículas com lubrificantes ou ceras, as quais reduzem a tendência de reabsorção de umidade, desde que obedecidas condições de armazenamento adequadas.

A madeira, enquanto constituinte de uma árvore viva, apresenta elevados teores de umidade, tipicamente entre $30 \%$ até $200 \%{ }^{[26]}$. Esta umidade é retirada através de diversos processos de secagem quando do condicionamento da madeira dita "verde" até chegar-se ao que se denomina madeira "seca". Simpson ${ }^{[27]}$ indica que os teores típicos de umidade da madeira seca ao ar variam entre 13 e $18 \%$ em peso, uma vez que este teor de umidade depende fortemente do ponto de equilíbrio alcançado com a umidade relativa do ar ambiente de seca- gem ou mesmo de uso da madeira. A madeira pode ser seca para níveis bastante menores. Porém, se não for garantida alguma forma de proteção, o gradiente de umidade em relação ao ambiente provocará o retorno ao ponto de equilíbrio em relação à umidade relativa do ar. Por este motivo o uso de resíduos de madeira industrializados na indústria de polímeros apresenta uma série de desafios. O teor de umidade tipicamente encontrado em "farinhas de madeira" comerciais entre 8 e $12 \%{ }^{[1]}$ é excessivamente elevado para a incorporação em matrizes termoplásticas. Matuana e Mengeloglu ${ }^{[28]}$ avaliaram a possibilidade desta umidade presente no reforço lignocelulósico ser utilizada como agente promotor de expansão em compósitos de PVC, porém a situação é bastante específica. No geral, a presença de umidade no reforço lignocelulósico traz uma série de dificuldades no processamento do compósito, terminando por provocar uma série de defeitos superficiais no produto final. Sombatsompop e Chaochanchaikul ${ }^{[29]}$ confirmam esta última observação.

Os equipamentos de extrusão de termoplásticos são normalmente dotados de etapas de degasagem, tanto através de simples abertura para a atmosfera (venting) quanto auxiliadas por potentes bombas de vácuo. O máximo teor de umidade admissível em uma farinha de madeira para processamento em matrizes poliméricas é de difícil definição e pouco divulgado pelos detentores das principais tecnologias de processamento, tais como as empresas Cincinnati Extrusion, Bausano Group, Kraus Maffei, Davis-Standard e Krupp Werner \& Pfleiderer. A depender da tecnologia da extrusora utilizada para o processamento do compósito lignocelulósico polimérico, considera-se aceitável um teor de umidade da madeira máximo de $8 \%{ }^{[30-33]}$. Um dos fatores afetados diretamente pelo teor de umidade do reforço lignocelulósico é a produtividade da linha de extrusão: quanto maiores os teores de umidade das partículas, menor a produtividade por conta do maior tempo de residência necessário para devolatilização do compósito.

A tecnologia para secagem industrial do reforço lignocelulósico e a proteção deste para minimizar a reabsorção de umidade também são propriedade intelectual dos detentores de tecnologia. É prática comum de mercado a venda de "pacotes tecnológicos" para a produção de perfis em compósito lignocelulósico de polímeros, pacotes estes que podem custar até mais de $€ 1$ milhão. É comum também o fornecimento de "farinhas de madeira" previamente secas e tratadas superficialmente com ceras e outros lubrificantes, tais como os tipos fornecidos pela empresa J. Rettenmaier \& Söhne (Alemanha), sob a marca comercial Lignocell ${ }^{\circledR}$, ou ainda pela American Wood Fibers (EUA). Alguns dos tipos fornecidos por estas empresas contem no máximo $2 \%$ de umidade, garantida por um processo de secagem industrial intensivo e proteção superficial das partículas com ceras e lubrificantes, além de prensagem na forma de grânulos para redução da área superficial exposta.

No Brasil, até o momento, não são fornecidas "farinhas de madeira" previamente secas até teores tão baixos de umidade, ficando os tipos disponíveis restritos a teores de umidade 
tipicamente acima de 7\%. Enquanto que nos EUA e Europa encontram-se disponíveis no mercado resíduos de madeira provenientes de espécies coníferas e folhosas, no Brasil são fornecidos no momento somente resíduos de coníferas (Pinus, Eucalipto e Araucária), moídos e selecionados através de peneiramento e parcialmente secos em processos simples. Isto exposto, fica evidente a relevância do desenvolvimento de uma tecnologia nacional para o tratamento de resíduos industrializados de madeira visando sua incorporação a matrizes poliméricas. A utilização de equipamentos convencionais da indústria de transformação de termoplásticos e de aditivos disponíveis no mercado permite alavancar o crescimento de participação de mercado desta nova geração de materiais, uma vez que as barreiras de capacidade de investimento do parque transformador nacional seriam menos relevantes que no caso da necessidade de aquisição de tecnologias caras como as citadas acima.

\section{Compósitos lignocelulósicos de PVC}

Segundo Agnelli[ ${ }^{[34]}$, compósitos poliméricos são materiais conjugados formados por pelo menos duas fases ou dois componentes, sendo geralmente uma fase polimérica denominada matriz polimérica e uma outra fase de reforço, normalmente na forma de fibras. Para a formação do material compósito ou do material conjugado é necessário haver uma interação química e/ou física entre a matriz polimérica e o reforço, proporcionando a transferência de esforços mecânicos da matriz polimérica para o reforço. A rigor, a própria madeira pode ser considerada um material conjugado: tal como visto anteriormente, sua microestrutura consiste basicamente de fibras de celulose em meio a uma matriz de lignina.

A incorporação de fibras de reforço em matrizes termoplásticas objetiva principalmente o aumento da resistência mecânica do polímero termoplástico. Existem vários formas de tratar a micromecânica dos compósitos, sendo que a aproximação mais simples é conhecida como Regra de Mistura, que considera as propriedades do compósito proporcional à fração volumétrica e às propriedades dos componentes, tal como mostrado nas eq. (1) e (2) ${ }^{[35]}$. Outros modelos mais complexos, com especificidades variadas, foram desenvolvidos por diversos pesquisadores ${ }^{[36-38]}$, e não foram objeto de detalhamento neste projeto de pesquisa.

As equações (1) e (2) foram desenvolvidas considerandose um regime de deformação da matriz e do reforço dentro do limite elástico e que a adesão entre ambos é perfeita. A primeira equação considera o perfeito alinhamento das fibras de reforço no sentido da aplicação do esforço, enquanto que a segunda equação considera a orientação das fibras no sentido transversal. Desta forma, o modelo considera as duas situações-limite de carregamento sendo que, para compósitos reais, nos quais a orientação das fibras apresenta algum grau de aleatoriedade quanto à orientação, é esperado que o módulo de elasticidade esteja compreendido na região delimitada pelas equações (1) e (2).

$$
\mathrm{E}_{\mathrm{c}, \mathrm{l}}=\mathrm{E}_{\mathrm{m}} \phi_{\mathrm{m}}+\mathrm{E}_{\mathrm{f}} \phi_{\mathrm{f}}=\mathrm{E}_{\mathrm{m}}\left(1-\phi_{\mathrm{f}}\right)+\mathrm{E}_{\mathrm{f}} \phi_{\mathrm{f}}
$$

$$
E_{c, t}=\frac{E_{m} E_{f}}{E_{f} \phi_{m}+E_{m} \phi_{f}}=\frac{E_{m} E_{f}}{E_{f}\left(1-\phi_{f}\right)+E_{m} \phi_{f}}
$$

Onde $E_{c, l}$ e $E_{c, t}$ representam os módulos de elasticidade do compósito no sentido longitudinal e transversal, respectivamente, $E_{m}$ e $E_{f}$ representem os módulos de elasticidade da matriz e do reforço, respectivamente, e $\phi_{m}$ e $\phi_{f}$ representam as frações volumétricas da matriz e do reforço, respectivamente.

A utilização de materiais sólidos como a madeira para a produção de perfis complexos não é a melhor proposição em termos de custo/benefício. As técnicas tradicionais de usinagem da madeira, tais como corte e desbaste, promovem perdas significativas de material, principalmente na forma de resíduo fino ("serragem"), material sem uso de alto valor comercial, sendo normalmente empregado em processos industriais como fonte de calor (queima). Aliado a isto existe o fato de que o custo da madeira, apesar de ainda pouco sentido no Brasil, tende a crescer no futuro, principalmente por conta de sua escassez crescente. Espera-se, portanto, que a madeira deva mudar seu perfil de utilização para produtos cada vez mais nobres, restando a alternativa de dar uma destinação mais adequada aos seus resíduos na forma de produtos com algum mínimo valor agregado. Alguns autores ${ }^{[39-41]}$ mencionam, inclusive, que o desenvolvimento de novas tecnologias de polímeros reforçados com reforços lignocelulósicos serão um dos vetores do crescimento do mercado de plásticos nos próximos anos.

Polímeros carregados com reforços lignocelulósicos fazem parte de uma nova classe de materiais que combina os atributos favoráveis tanto da madeira quanto dos plásticos. No caso específico do PVC, seus compósitos lignocelulósicos exibem atributos bastante favoráveis tais como facilidade de processamento em equipamentos disponíveis no parque industrial brasileiro, além de características interessantes para aplicações na construção civil tais como resistência à umidade e a insetos, resistência ao intemperismo, baixa absorção de umidade, possibilidade de soldagem de perfis nos cantos (processo semelhante ao utilizado na montagem de esquadrias de PVC), além da possibilidade de sofrer processos tipicamente utilizados na madeira como colagem, montagem por pregos ou parafusos auto-atarraxantes, pintura (somente caso desejado), dentre outras ${ }^{[42-45]}$. Na Europa compósitos lignocelulósicos de PVC reciclado têm suportado a indústria de transformação deste material no esforço de aumento das taxas de reciclagem deste polímero ${ }^{[46]}$.

Compósitos lignocelulósicos de PVC, entretanto, apresentam baixos valores de módulo de elasticidade na flexão, o que limita seu uso em aplicações estruturais, tais como vigas e colunas $^{[41]}$. Isto se deve ao fato do PVC rígido, tal como a maioria dos polímeros orgânicos, apresentar baixo módulo de elasticidade em comparação com a madeira: enquanto o PVC rígido apresenta módulo de elasticidade na flexão da ordem de 2,0 a 3,5 $\mathrm{GPa}$, tal como visto anteriormente, as madeiras, de comportamento ortotrópico, apresentam ampla faixa de valores, variando entre 7,7 e $15,0 \mathrm{GPa}^{[47]}$. Entretan- 
to, a aplicação de compósitos lignocelulósicos de PVC é viável em aplicações não-estruturais, tais como perfis de decoração e acabamento.

Apesar de diversas similaridades, existem diferentes tipos de compósitos lignocelulósicos de polímeros, cada qual com suas particularidades. A maior parte das diferenças mais significativas resultam da matriz polimérica selecionada e do tipo/quantidade de madeira incorporados. Polietilenos (PE), PVC e polipropileno (PP) são as principais matrizes termoplásticas utilizadas nestes compósitos, cada qual com seu balanço de vantagens e desvantagens. PE e PP, polímeros de baixa viscosidade no estado fundido, normalmente apresentam elevada capacidade de incorporação de madeira, em teores que podem chegar a $80-85 \%$ em massa ${ }^{[33]}$. No PVC, em função da elevada viscosidade deste polímero quando no estado fundido, os teores máximos de incorporação são menores, limitando-se a $60 \%$ em massa ${ }^{[32,48,49]}$. Compósitos de PE ou PP, normalmente reciclados pós-consumo, podem apresentar menores custos de produção que similares em PVC, polímero para o qual a disponibilidade de material reciclado pós-consumo é menor em função de sua aplicação em produtos de longo ciclo de vida ${ }^{[50]}$. O PVC, por sua vez, apresenta vantagens sobre estes outros dois polímeros em três aspectos principais e relevantes:

(a) Maior módulo de elasticidade (maior rigidez) da matriz polimérica: enquanto o $\mathrm{PVC}$ apresenta, como já comentado, módulo de elasticidade da ordem de 2, 0 a 3,5 GPa, tanto o PE quanto o PP são menos rígidos, com módulos de elasticidade entre 1,0 e $1,5 \mathrm{GPa}^{[35]}$.

(b) Baixa inflamabilidade inerente do PVC: as resinas de PVC são compostas por $57 \%$ de cloro e $43 \%$ de etileno, o que as tornam inerentemente pouco inflamáveis, aspecto importante na seleção de materiais para uso na construção civil.

(c) Possibilidade de pintura: a presença do cloro na estrutura química do PVC torna-o superficialmente bastante polar, principalmente quando comparado com o PE e o PP, polímeros de baixa polaridade superficial e pouca interação química. Desta forma, produtos em compósito lignocelulósico de PVC podem ser pintados sem a necessidade de tratamento superficial prévio.

\section{Desenvolvimento de uma formulação para PVC modificado com farinha de madeira}

Um experimento ${ }^{[7]}$ realizado pelos autores consistiu na avaliação dos efeitos da incorporação de diferentes teores de resíduo de madeira industrializado em um composto de PVC rígido tomado como referência. Dois tipos de resíduo de madeira, de diferentes tamanhos médios de partícula, foram secos e tratados segundo um procedimento padronizado e utilizando-se de dois tipos de tratamento superficial das partículas lignocelulósicas. As quatro alternativas de reforço lignocelulósico, em função do tipo de madeira e tratamento realizado, foram incorporadas em um composto rígido de $\mathrm{PVC}$ referência em concentrações mássicas variando entre 10 e $60 \%$.

Resina de PVC com valor K 61 (Norvic ${ }^{\circledR}$ SP 800, fornecida
Tabela 1. Formulação do composto de PVC utilizada no experimento. Os teores encontram-se denotados em pcr (partes em peso de cada ingrediente em cada 100 partes em peso de resina de PVC)

\begin{tabular}{|c|c|c|}
\hline Ingrediente & Teor (pcr) & Função na formulação \\
\hline Norvic $^{\circledR}$ SP 800 & 100 & $\begin{array}{c}\text { Resina de PVC, valor K } 61 \\
\text { (matriz polimérica) }\end{array}$ \\
\hline Naftosafe ${ }^{\circledR}$ CZ-4004 & 4 & $\begin{array}{l}\text { Estabilizante térmico base } \\
\text { cálcio/zinco }\end{array}$ \\
\hline KaneAce ${ }^{\circledR}$ PA-40 & 1 & $\begin{array}{c}\text { Modificador de fluxo } \\
\text { (auxiliar de processamento) } \\
\text { base acrílico }\end{array}$ \\
\hline KaneAce ${ }^{\circledR}$ FM-40 & 8 & $\begin{array}{l}\text { Modificador de impacto } \\
\text { base acrílico }\end{array}$ \\
\hline Tinuvin ${ }^{\circledR} \mathrm{P}$ & 0,7 & $\begin{array}{l}\text { Absorvedor de ultravioleta } \\
\text { base benzotriazol }\end{array}$ \\
\hline
\end{tabular}

pela Braskem S/A) foi utilizada como matriz polimérica principal. A estabilização da formulação foi efetuada através da incorporação de um estabilizante térmico base cálcio/zinco. Foram ainda incorporados modificadores de impacto e auxiliares de processamento acrílicos. A composição principal da formulação é apresentada na Tabela 1.

Como reforço lignocelulósico foram utilizados resíduos industrializados de mistura de Pinus elliottii e Pinus taeda procedentes da Pinhopó Moagem de Madeiras Ltda. Foram seleciona dois tipos de "farinha de madeira" considerandose o tamanho médio e distribuição de tamanho de partículas: tipo M04C ( $80 \%$ das partículas retidas em malha 60 mesh ou $250 \mu \mathrm{m}$, ou seja, de partículas mais grosseiras), e tipo M10045 (95\% das partículas passam em malha 100 mesh ou $150 \mu \mathrm{m}$, ou seja, de partículas bastante finas). Desta forma, tornou-se possível uma comparação dos efeitos do tamanho médio e distribuição de tamanho de partículas quando da incorporação ao composto rígido de PVC tomado como referência.

O resíduo de madeira foi seco utilizando-se de uma técnica descrita em outros trabalhos ${ }^{[7,16,51,52]}$. Este processo consistiu da secagem do resíduo de madeira no próprio misturador intensivo responsável pela incorporação e homogeneização dos aditivos. Durante a secagem foram incorporados os lubrificantes funcionais e os demais agentes de tratamento superficial das partículas do reforço lignocelulósico visando a redução da tendência de reabsorção de umidade pelas mesmas. Foram adotadas duas alternativas de tratamento superficial das partículas lignocelulósicas:

(a) Tratamento do reforço lignocelulósico com 1,5\% em massa de Struktol ${ }^{\circledR}$ TPW0012 (Struktol, EUA), lubrificante funcional recomendado especificamente para compósitos de termoplásticos com madeira ${ }^{[33]}$;

(b) Tratamento do reforço lignocelulósico com uma mistura de lubrificantes funcionais e agentes de acoplamento. As partículas foram tratadas com 1,5\% de Struktol ${ }^{\circledR}$ TPW0012 e 1,0\% de organotitanato Lica ${ }^{\circledR} 38$ (tri(dioctil) pirofosfato tinanato, fornecido pela Kenrich Petrochemicals, EUA).

Os efeitos da incorporação do reforço lignocelulósico à 
processabilidade do PVC rígido foram avaliados através do procedimento descrito na ASTM D2538 ${ }^{[53]}$. Os ensaios foram conduzidos em um reômetro de torque ThermoHaake modelo Polylab System Rheocord 300p, dotado de uma câmara de mistura Rheomix 610P e rotores tipo Roller.

A temperatura da câmara foi estabelecida em $180^{\circ} \mathrm{C}$, enquanto que a velocidade angular dos rotores foi constante em $20 \mathrm{~min}^{-1}$. O tempo total de ensaio para todas as formulações foi de 16 min. Os ensaios realizados foram importantes para a determinação das temperaturas e energias necessárias para o início do processo de gelificação e fusão do composto de PVC. Foram ainda determinados valores de taxa (velocidade) de gelificação.

A preparação de corpos de prova para caracterização mecânica e térmica foi realizada através da plastificação das formulações em uma calandra de dois rolos, na temperatura de $190^{\circ} \mathrm{C}$. Placas do compósito lignocelulósico de PVC foram obtidas via prensagem a quente do material proveniente da calandra na temperatura de $170{ }^{\circ} \mathrm{C}$. Corpos de prova para determinação da resistência ao impacto Charpy ${ }^{[54]}$ e resistência à flexão em três pontos $^{[55]}$ foram usinados de placas em uma fresadora Ceast. Todos os corpos de prova foram condicionados por um mínimo de $40 \mathrm{~h}$ na temperatura de $(23 \pm 2){ }^{\circ} \mathrm{Ce}(50 \pm 5) \%$ de umidade relativa do ar, segundo as recomendações do procedimento ASTM D618 ${ }^{[56]}$, antes da realização dos ensaios.

As superfícies de fratura de corpos de prova ensaiados para a determinação da resistência ao impacto Charpy foram avaliadas através de microscopia eletrônica de varredura.

\section{Eficiência do tratamento do resíduo de madeira Pinus}

$\mathrm{O}$ experimento demonstrou que o processo de tratamento proposto $^{[7]}$ é eficiente. Teores de umidade presentes nas partículas lignocelulósicas em seu estado normal de fornecimento, superiores a $7 \%$, foram reduzidos para valores entre $1 \mathrm{e}$ $2 \%$ utilizando-se equipamentos convencionais da indústria do PVC, mostrando que o processo de tratamento desenvolvido traz ambos os reforços lignocelulósicos para teores de umidade relativamente baixos, adequados ao processamento por extrusão no caso de máquinas dotadas de degasagem ${ }^{[57]}$.

\section{Processabilidade do composto de PVC modificado com farinha de madeira}

A presença de farinha de madeira reduz sensivelmente a velocidade de gelificação do PVC nas formulações ensaiadas, como pode ser observado na Figura 1. Este fenômeno ocorre pois o processo de gelificação e fusão de compostos de PVC depende do atrito interpartícula da resina polimérica, o aumento da fração de carga no composto provoca afastamento crescente das partículas de resina de PVC, dificultando o processo de transição entre grãos individuais para uma estrutura de partículas primárias sinterizadas no estado pré-fusão ${ }^{[58-60]}$.

\section{Propriedades mecânicas das formulações PVC/farinha de madeira preparadas}

Como seria de se esperar a resistência ao impacto Charpy dos compostos de PVC foi reduzida pela presença da farinha

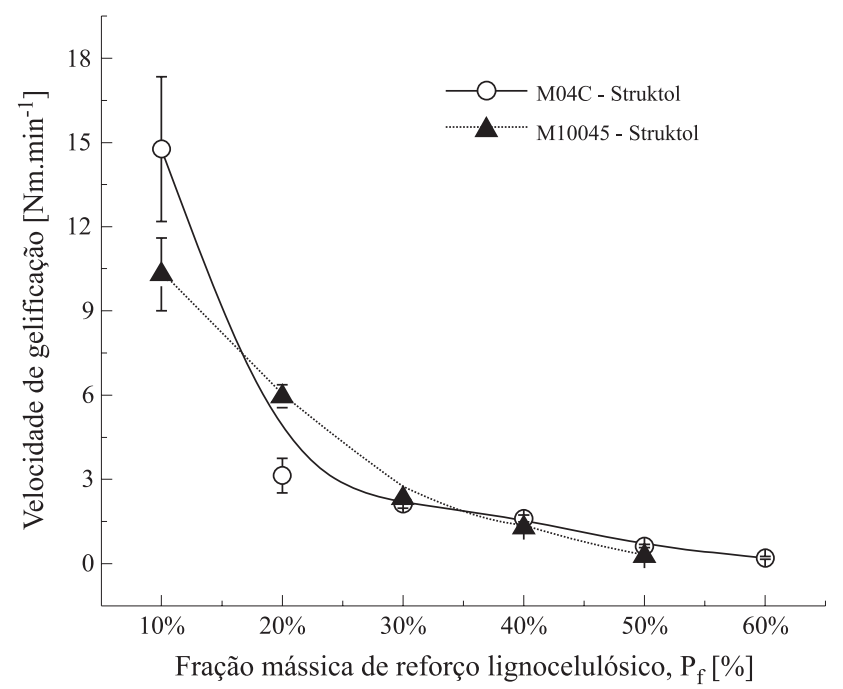

Figura 1. Efeito da fração mássica de reforço lignocelulósico na velocidade de gelificação das formulações

de madeira, pois este componente aumenta a fragilidade do composto final. Não foram observados efeitos significativos do tratamento superficial das partículas com organotitanatos, uma vez que o desempenho destas formulações foi o mesmo que o das formulações tratadas somente com o lubrificante funcional Struktol. As formulações tratadas com o reforço lignocelulósico tipo M04C apresentaram resultados superiores de resistência ao impacto Charpy que formulações equivalentes que utilizaram o tipo M10045. Pode-se atribuir este resultado à maior continuidade da matriz de $\mathrm{PVC}$ no caso do reforço lignocelulósico tipo M04C, de maior tamanho médio de partícula, em comparação com o tipo M10045 que, em função do menor tamanho médio de partícula, afetou de forma mais pronunciada a continuidade da matriz dúctil de PVC.

A micrografia obtida por microscopia eletrônica de varredura apresentada na Figura 3 mostra a superfície de um corpo de prova fraturado no ensaio de impacto Charpy. Observa-se que o reforço lignocelulósico comporta-se como carga

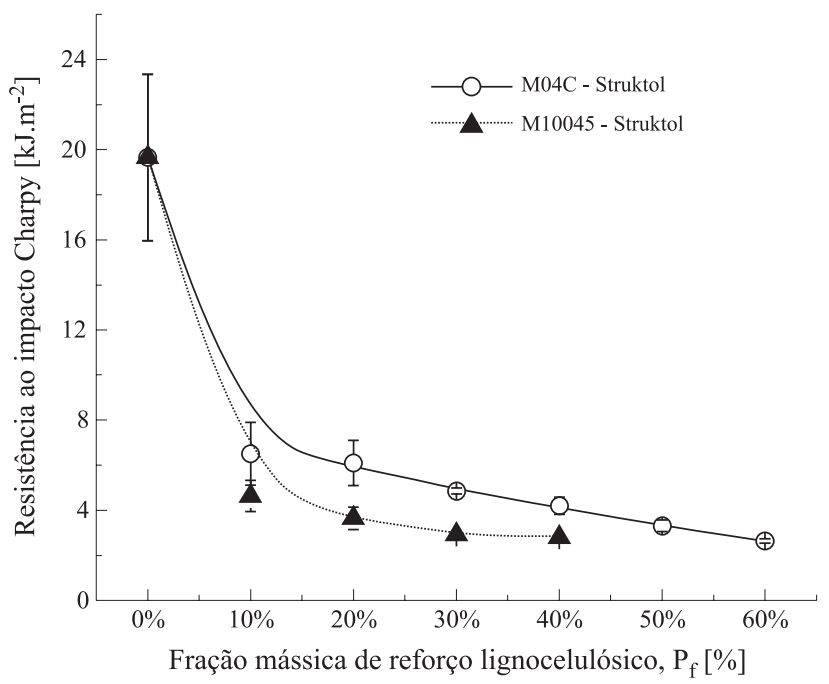

Figura 2. Efeito da fração mássica de reforço lignocelulósico na energia de impacto Charpy necessária à fratura das formulações 


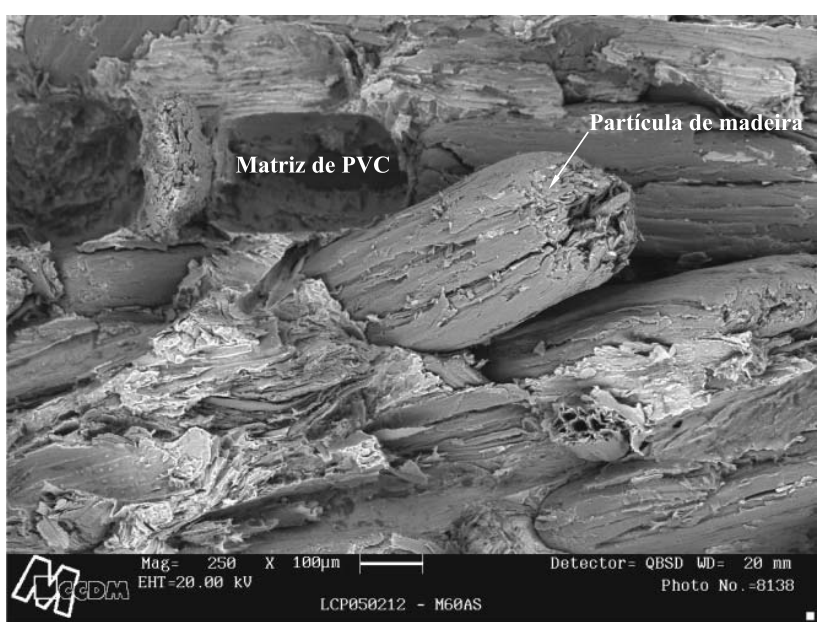

Figura 3. Micrografia obtida por microscopia eletrônica de varredura da formulação contendo $60 \%$ em massa de reforço lignocelulósico tipo M04C tratado com Struktol. Ampliação de 250x

de enchimento ao invés de fibra de reforço no sentido estrito da palavra, uma vez que não se observam partículas fraturadas mas sim arrancadas da matriz de PVC. É possível observar os vazios deixados na matriz de PVC pelo arrancamento das partículas de sua posição original no momento da fratura.

Parte da grande incidência de arrancamento das patículas é explicada pelo seu fator de forma desfavorável. Uma vez que não se tratam de fibras propriamente ditas, a área de contato entre as partículas lignocelulósicas a matriz de PVC é limitada, reduzindo-se a força necessária para o arrancamento das mesmas. Além do mais, verifica-se que a aderência na interface é deficiente, haja visto que verifica-se o descolamento das partículas da matriz em todos os casos analisados.

A partir dos resultados obtidos para a densidade das diferentes formulações foi possível determinar-se, para cada formulação, a fração volumétrica $\phi_{f}$ de reforço incorporada ${ }^{[22]}$. O modelo da Regra da Mistura contempla ainda o módulo de elasticidade da matriz $E_{m}$, neste caso o módulo de elasticidade do composto referência $\left(\mathrm{E}_{\mathrm{m}}=2,72 \mathrm{GPa}\right)$, e o módulo de elasticidade $E_{f}$ do reforço. A real composição dos reforços lignocelulósicos utilizados é desconhecida, uma vez que se sabe somente tratar-se de uma mistura de partículas derivadas de Pinus elliottii e Pinus taeda, conforme informações do fornecedor. Considerou-se uma mistura hipotética de 50\% de partículas de Pinus elliottii e 50\% de partículas de Pinus taeda, de tal forma que o módulo de elasticidade $E_{f}$ do reforço fosse a média dos módulos de elasticidade destas duas madeiras no sentido longitudinal das fibras lignocelulósicas. Desta forma, para fins de verificação da adequação dos resultados obtidos ao modelo da Regra da Mistura, considerou-se $\mathrm{E}_{\mathrm{f}}=13,0 \mathrm{MPa}$, conforme dados obtidos na literatura ${ }^{[61]}$.

A Figura 4 mostra que os dados de módulo de elasticidade na flexão, para frações mássicas de reforço lignocelulósico menores ou iguais à 50\%, apresentam excelente adequação ao modelo da Regra da Mistura, uma vez que os pontos, independentemente do tipo de partícula ou do tratamento utilizado, encontram-se na região delimitada pelas eq. (1) e (2).

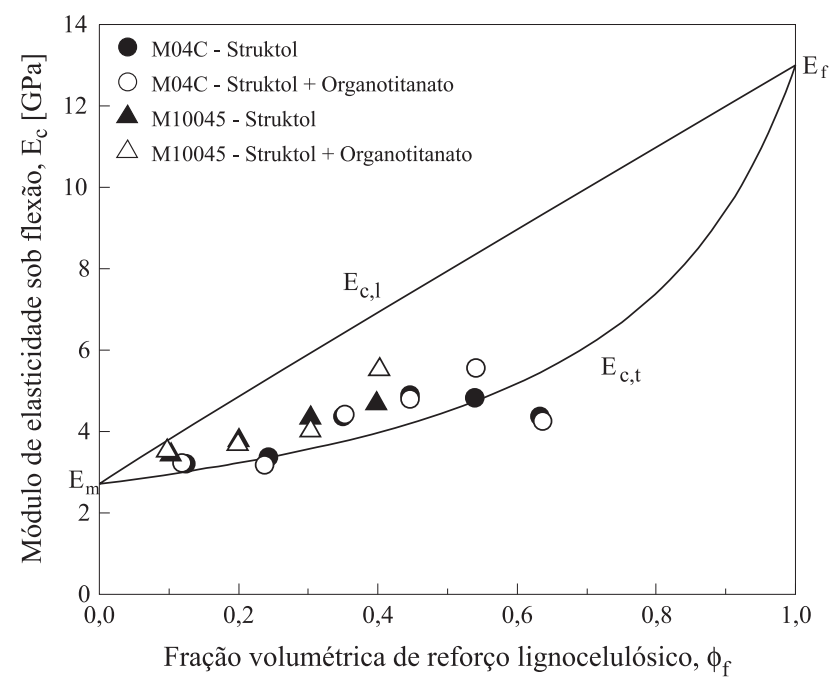

Figura 4. Aplicação do modelo da Regra da Mistura, conforme apresentado nas eq. (1) e (2), aos resultados obtidos para o módulo de elasticidade das diferentes formulações de compósito lignocelulósico de PVC avaliadas neste estudo

Para o caso do reforço lignocelulósico tipo M04C, em ambos os tipos de tratamento e na fração mássica $60 \%$, verificase que o módulo de elasticidade na flexão é inferior ao mínimo definido pelo modelo, reforçando a suspeita de que o excesso de partículas e a falta de adesão entre as mesmas e a matriz comprometeram a microestrutura do compósito.

\section{Principais conclusões sobre o desenvolvimento do composto PVC/farinha de madeira}

$\mathrm{O}$ experimento relatado demonstrou que o tratamento de dois tipos de reforço lignocelulósico, cada qual com seu perfil de distribuição de tamanho de partículas, quando realizado de acordo com o procedimento detalhado, pode ser eficiente, mesmo utilizando-se de equipamentos absolutamente convencionais da indústria do PVC.

Não foram observadas diferenças estatisticamente significativas quanto às propriedades finais do compósito em função do tipo de tratamento superficial conferido ao reforço lignocelulósico. Todas as formulações apresentaram baixo grau de adesão entre a matriz de PVC e as partículas lignocelulósicas, o que faz com que o tratamento com o agente de acoplamento selecionado neste estudo tenha se mostrado inócuo no aspecto adesão matriz/reforço.

O aumento da concentração de reforço lignocelulósico incorporado à matriz dificultou o processamento, denotado pelo aumento do tempo necessário à fusão da matriz de PVC, menor velocidade de gelificação, maior temperatura necessária à fusão e maior demanda de energia de processamento.

Tal como esperado pelo modelo da Regra da Mistura para o comportamento do módulo de elasticidade, a incorporação de frações mássicas crescentes de reforço lignocelulósico na matriz de PVC, até um limite de 50\%, provocaram o aumento do módulo de elasticidade do compósito sob flexão.

Os reforços lignocelulósicos avaliados neste estudo não podem ser considerados "fibras" no sentido estrito da palavra, uma vez que seu fator de forma é desfavorável, ou seja, 

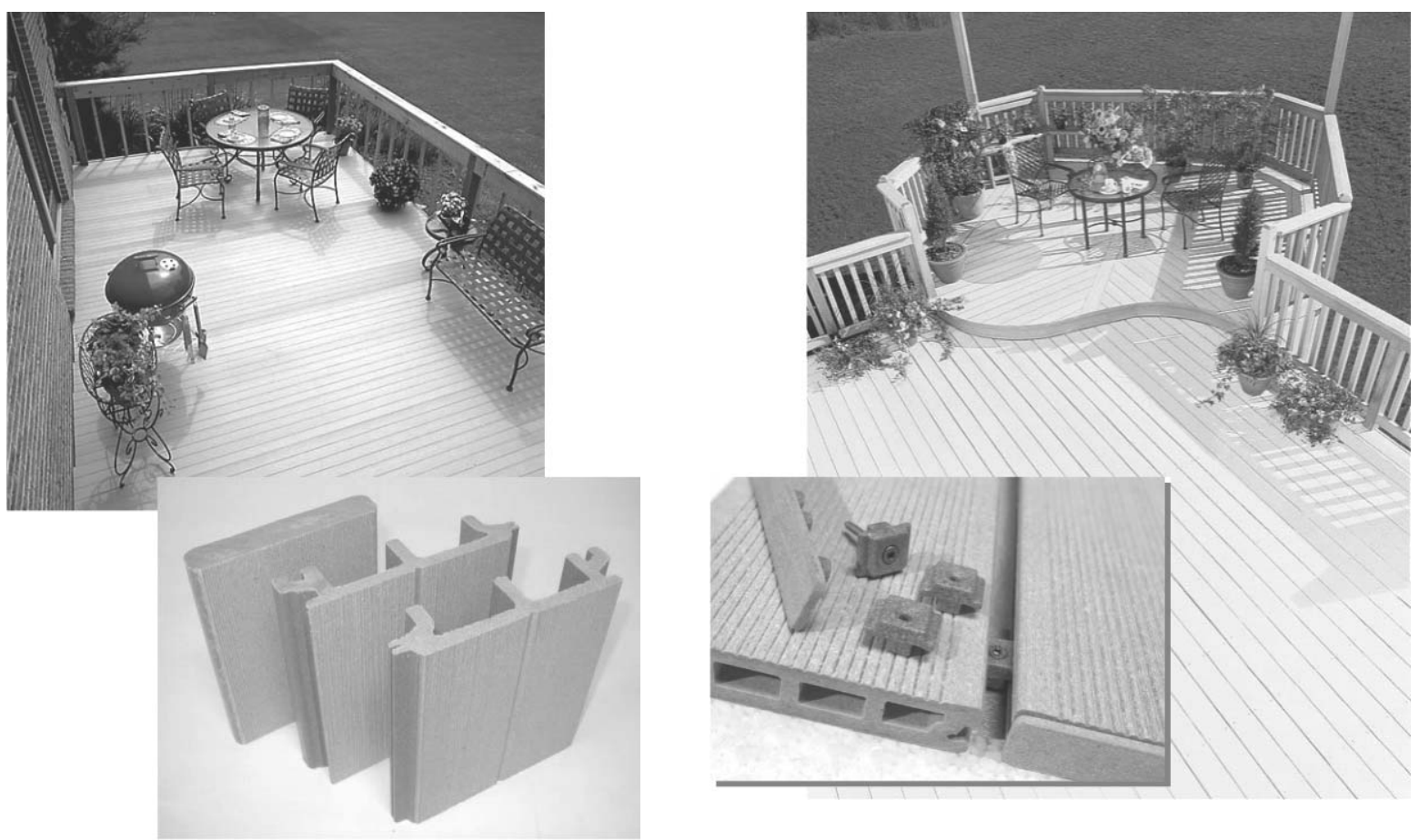

Figura 5. Exemplos de aplicação de compostos PVC/farinha de madeira como perfis para fabricação de decks

o comprimento das partículas de madeira é curto para que permita a observação de algum efeito de reforço da matriz. Resultados de resistência ao impacto Charpy e energia de fratura na flexão mostram que as partículas atuam na verdade como carga de enchimento da matriz de PVC.

\section{Alternativas para aplicações do composto PVC/farinha de madeira}

A utilização do composto PVC/farinha de madeira na substituição de madeira convencional já é uma realidade, porém as oportunidades ainda estão longe de se esgotar. Aplicações em decks, como apresentado na Figura 5 são muito convenientes, pois a durabilidade sob intempéries do composto é superior à da madeira, fazendo com que os componentes necessitem de menos manutenção que no caso de materiais tra-

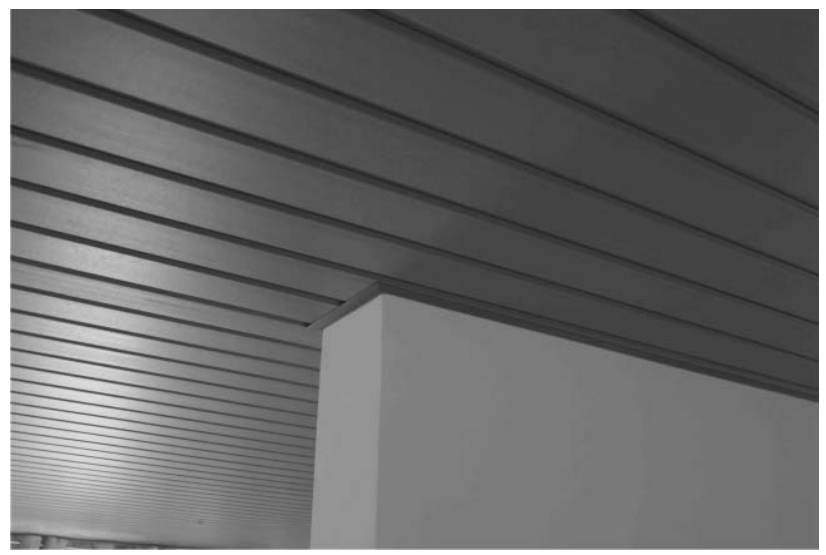

Figura 6. Exemplos de aplicação de compostos PVC/farinha de madeira na fabricação de forros (WoodCell ${ }^{\circledR}$ Araforros) dicionais. Além disso, os perfis fabricados são muito versáteis quanto ao design e quanto ao acabamento das peças desenvolvidas a partir dos perfis. Formulações de PVC compactas e expandidas podem ser utilizadas, permitindo ainda mais versatilidade no desenvolvimento de novas aplicações.

A incorporação de farinha de madeira em compostos de PVC para a confecção de forros de PVC já é uma realidade através do produto lançado pela empresa brasileira Araforros com o nome comercial de $W_{o o d C e l l}{ }^{\circledR}$, cuja ilustração é apresentada na Figura 6. Este tipo de alternativa para forros também é muito conveniente tanto do ponto de vista estético como funcional. A estética do forro de PVC/farinha de madeira possibilita a reprodução da textura da madeira, assim como o uso do composto de PVC modificado com madeira pode alterar o conforto térmico do ambiente pela mudança do fator de isolamento térmico do mesmo.

Uma das áreas de aplicação onde a substituição da madeira pelo composto $\mathrm{PVC/farinha} \mathrm{de} \mathrm{madeira} \mathrm{ainda} \mathrm{não} \mathrm{foi} \mathrm{de-}$ vidamente explorada é na fabricação de móveis. A indústria moveleira utiliza vários tipos e formas de madeira, porém a quantidade de resíduos gerados pelo processo de usinagem das peças fabricadas em madeira proporciona desvantagens econômicas, bem como problemas ambientais na extração de madeiras nativas e descarte dos resíduos gerados no processo de desbaste. A alternativa de uso de perfis e peças injetadas de compostos de PVC/farinha de madeira proporciona o abrandamento e a eliminação destas inconveniências, além de mostrar novas alternativas de design. O volume de material composto de PVC necessário para enfrentar este desafio é quase incalculável. A Figura 7 apresenta uma ilustração so- 


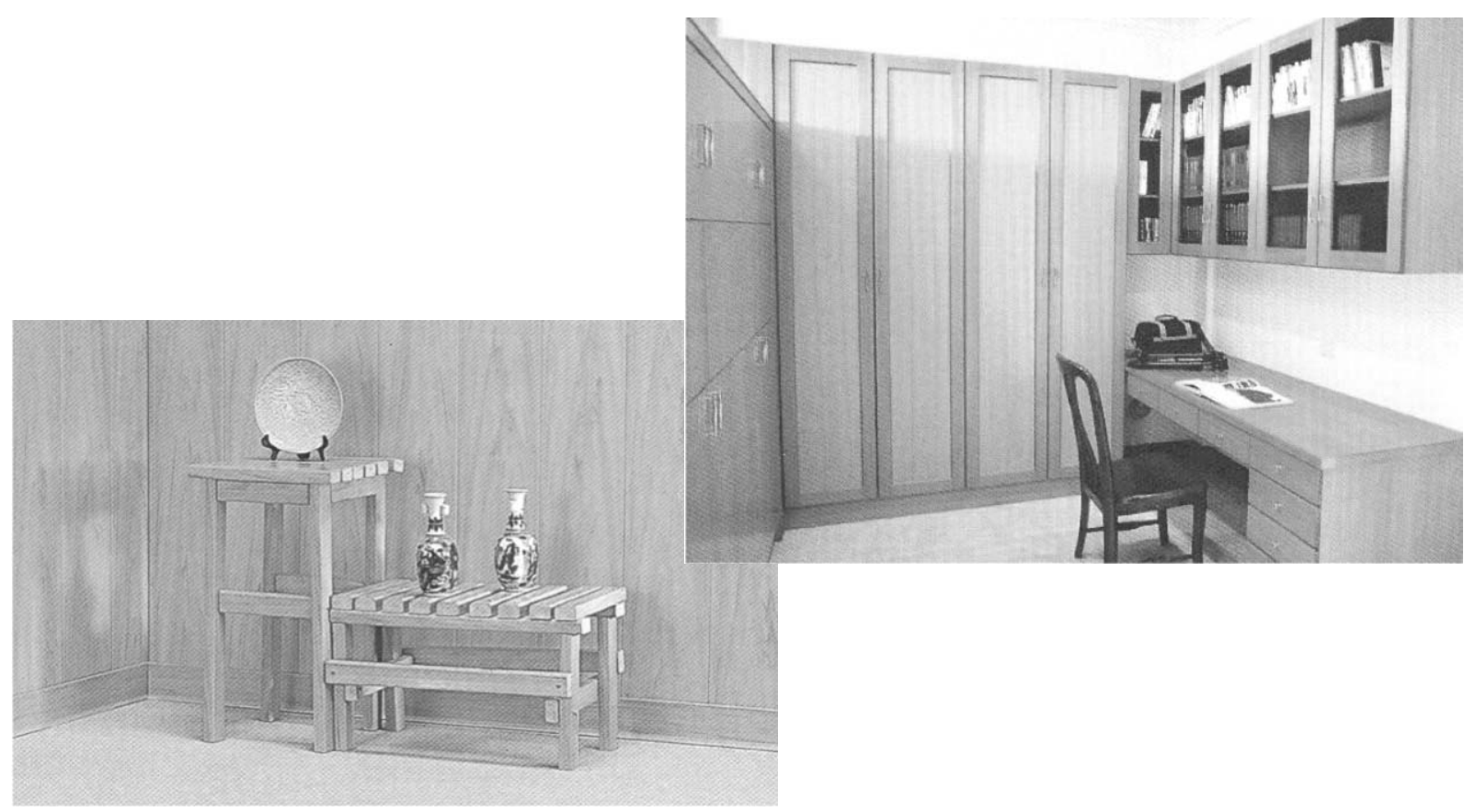

Figura 7. Possibilidades para aplicação de compostos PVC/farinha de madeira na fabricação de móveis.

bre a possibilidade de produção de artefatos a partir do composto $\mathrm{PVC} /$ farinha de madeira para a indústria moveleira.

\section{Agradecimentos}

Os autores agradecem à Braskem S/A pela permissão de publicação deste estudo.

\section{Referências bibliográficas}

1. Jiang, H.; Kamdem, P. - J. Vinyl Addit. Techn., 10, p.59 (2004).

2. Patterson, J. - J. Vinyl Addit. Techn., 7, p.138 (2001).

3. Jiang, H. et al. - J. Vinyl Addit. Techn., 9, p.138 (2003).

4. Deligio, T. - Mod. Plastics Int., 34 (8), p.26 (2004).

5. Helsen, L.; Van den Bulck, E. - Env. Pollution, 134, p.301 (2005).

6. Leaversuch, R. D. - Mod. Plastics Int., 73, p.52 (1996).

7. Rodolfo Jr., A. - "Estudo da processabilidade e das propriedades de PVC reforçado com resíduos de Pinus", Dissertação de Mestrado, Escola Politécnica da Universidade de São Paulo, Brasil (2005).

8. CMAI - "2003 world vinyl analysis", Houston, Chemical Market Associates, Inc. (2003).

9. Mattoso, L. H. C.; Ferreira, F. C.; Curvelo, A. A. S. - "Sisal fiber: morphology and applications in polymer composites", in: Lignocellulosic-plastics composites, p.241, Leão, A. L.; Carvalho, F. X.; Frollini, E. (ed), São Paulo, USP, Botucatu, UNESP (1997).
10. Martin, A. R. et al. - "Plasma modification of sisal on high density polyethylene composites: effect on mechanical properties", in: Proceedings from the Third International Symposium on Natural Polymers and Composites - ISNaPol/2000, p.431, Mattoso, L. H. C.; Leão, A. L.; Frollini, E. (ed), São Carlos, Embrapa Instrumentação Agropecuária (2000).

11. Friollini, E. ; Leão, A. L. ; Mattoso, L. H. C. - "Natural polymers and agrofiber based composites", São Carlos, USP-IQSC/Embrapa Instrumentação Agropecuária, Botucatu, UNESP (2000).

12. Martins, G. S. et al. - Polímeros, 14, p.326 (2004).

13. Cruz, C. V. M. S. - "Emprego do delineamento de experimentos para o desenvolvimento de compósitos de polipropileno/fibra de sisal”, Dissertação de Mestrado, Departamento de Engenharia de Materiais da Universidade Federal de São Carlos, Brasil (2002).

14. Sato, A. G.; Hage Jr. E.; Rodolfo Jr., A. - "Desenvolvimento de compostos de PVC rígido com pó de madeira", in: Feira e Congresso Plastshow 2002, São Paulo (2002).

15. Sato, A. G.; Hage Jr. E.; Rodolfo Jr., A. "Desenvolvimento de compostos de PVC rígido com pó de madeira: efeito do tratamento da carga quanto a desempenho mecânico e processabilidade" in: Congresso em Ciência de Materiais do Mercosul SULMAT, Joinville (2002).

16. Sato, A. G. - "Desenvolvimento de compostos de PVC rígido com pó de madeira", Dissertação de Mestrado, Departamento de Engenharia de Materiais da Universidade Federal de São Carlos, Brasil (2005). 
17. Desiderá, C. - "Avaliação de compósitos de poliestireno de alto impacto reciclado e resíduos de madeiras de reflorestamento (Eucaliptus e Pinus)" Dissertação de Mestrado, Departamento de Engenharia de Materiais da Universidade Federal de São Carlos, Brasil (2003).

18. Joseph, K. et al. - Revista Brasileira de Engenharia Agrícola e Ambiental, 3, p.367 (1999).

19. Joseph, K.; Mattoso, L. H. C. - "Sisal fibre reinforced polymer composite: status and future", in: Proceedings from the Third International Symposium on Natural Polymers and Composites - ISNaPol/2000, p.333, Mattoso, L. H. C.; Leão, A. L.; Frollini, E. (ed), São Carlos, Embrapa Instrumentação Agropecuária (2000).

20. Suarez, J. C. M.; Coutinho, F. M. B.; Sydenstricker, T. H. - Polímeros, 15, p.139 (2005).

21. Bonelli, C. M. C. et al. - Polímeros, 15, p.256 (2005).

22. Vianna, W. L.; Correa, C. A.; Razzino, C. A. - Polímeros, 14, p.339 (2004).

23. Pesquisa Fapesp, 108, p.65 (2005).

24. Téchne, 13, p.10 (2005).

25. Sanadi, A. R.; Caulfield, D. F.; Rowell, R. M. - The Fibril Angle, Spring 1998, p.8 (1998)

26. Simpson, W.; Tenwolde, A. - "Physical properties and moisture relations of wood", in: Wood handbook, cap.3, Forest Products Laboratory (ed.), Forest Products Laboratory, Madison (1999).

27. Simpson, W. - "Drying and control of moisture content and dimensional changes", in: Wood handbook, cap.12, Forest Products Laboratory (ed.), Forest Products Laboratory, Madison (1999).

28. Matuana, L.; Mengeloglu, F. - J. Vinyl Addit. Techn., 8, p.264 (2002).

29. Sombatsompop, N; Chaochanchaikul, K. - Pol. Int., 53, p.1210 (2004).

30. Rider Jr., R. F.; Newton, O. A. - "Material handling for wood-plastic composites", in: Wood-plastic composites 2002, Viena (2002).

31. Sehnal, E. - "Fiberex ${ }^{\circledR}$ - Wood composite extruders", in: Wood-plastic composites 2002, Viena (2002).

32. Smutka, F. - "Woodextrusion - advanced technologies", in: Wood-plastic composites 2002, Viena (2002).

33. Fulmer, M. - "The effects of various processing additives on the processing and physical properties of woodfilled PVC", in: Wood-plastic conference 2000, Baltimore (2000).

34. Agnelli, J. A. M. - "Curso aperfeiçoamento em tecnologia de polímeros. Módulo 1. Introdução a materiais polimérico", São Carlos, Núcleo de Reologia e Processamento de Polímeros (2000).

35. Callister Jr., W. D. - "Ciência e engenharia de materiais. Uma introdução", 5.ed., LTC, Rio de Janeiro (2002).

36. Nielsen, L. E. - "Mechanical properties of polymers and composites", Nova York, Marcel Dekker (1974).

37. Ferrigno, T. H. - "Principles of filler selection and use", in: Handbook of fillers for plastics, p. 8, Katz, H. S.; Milewski, J. V. (ed.), Nova York, Van Nostrand Reinhold (1987).

38. Chawla, K. K. - "Composite materials: science and engineering", 2. ed., Nova York, Springer-Verlag (1998).

39. Goodman, D. - "PVC markets, today and in 2020", in: ANTEC 1998, Atlanta (1998).

40. Pardos, F. - "Plastics in the world to 2020", in: ANTEC 1999, Nova York (1999).

41. Goldsberry, C. - Mod. Plastics Int., 34, p.26 (2004).

42. Chetanachan, W. et al. - J. Vinyl Addit. Techn., 7, p.134 (2001).

43. Koenig, S. R.; Williams, R. K. - "Thermoplastic bio-fiber composite: ideation through product commercialization", in: ANTEC 2002, São Francisco (2002).

44. Patterson, J. - J. Vinyl Addit. Techn., 7, p.138 (2001).

45. Pritchard, G. - Plast. Addit. Compound., 6, p.18 (2004).

46. Markarian, J. - Plast. Addit. Compound., 5, p.24 (2003).

47. Wilcox, W. W.; Botsai, E. E.; Kubler, H. - "Wood as a building material: a guide for designers and builders", Nova York, John Wiley \& Sons (1991).

48. Jackson, S. M. - "Advanced processing technology for manufacturing wood-polymer composites", Werner \& Pfleiderer Corporation, Nova Jersey (2000).

49. Cincinnati Extrusion. - "Wood plastic composite extruder", Cincinnati Extrusion, Viena (2004).

50. Rodolfo Jr., A.; Nunes, L. R.; Ormanji, W. - "Tecnologia do PVC", ProEditores Associados, São Paulo (2002).

51. Rodolfo Jr., A.; John, V. M. - "Obtenção de compósitos de PVC e resíduo de Pinus: avaliação da viabilidade da substituição da madeira em perfis de acabamento na construção civil”, in: I Conferência Latino-Americana de Construção Sustentável e X Encontro Nacional de Tecnologia do Ambiente Construído, São Paulo (2004).

52. Rodolfo Jr., A.; John, V. M. - "Obtenção de compósitos de PVC e resíduo de Pinus: avaliação da viabilidade da substituição da madeira em perfis de acabamento na construção civil", in: Conferência Brasileira de Materiais e Tecnologias Não-Convencionais: 
Habitações e Infra-Estrutura de Interesse Social. Brasil NOCMAT, Pirassununga (2004).

53. American Society for Testing and Materials - "Standard practice for fusion of poly (vinyl chloride) (PVC) compounds using a torque rheometer; ASTM D2538", West Conshohocken (2002).

54. American Society for Testing and Materials - "Standard test methods for determining the Charpy impact resistance of notched specimens of plastics; ASTM D6110”, West Conshohocken (2004).

55. American Society for Testing and Materials - "Standard test methods for flexural properties of unreinforced and reinforced plastics and electrical insulating materials; ASTM D790", West Conshohocken (2003).

56. American Society for Testing and Materials - "Standard practice for conditioning plastics for testing and electrical insulating materials for testing; ASTM D618”, West Conshohocken (2000).

57. Rauwendaal, C. - “Understanding extrusion”, Hanser/ Gardner, Cincinnati (1998).

58. Faulkner, P. G. - J. Mol. Sci. - Phis. B., 11, p.251 (1975).

59. Rabinowitch, E. B.; Summers, J. - J. Vinyl Techn., 2, p.165 (1980).

60. Summers, J. - J. Vinyl Addit. Techn., 3, p.130 (1997).

61. Green, D. W.; Winandy, J. E.; Kretschmann, D. E. "Mechanical properties of wood", in: Wood handbook, cap.4, Forest Products Laboratory (ed.), Forest Products Laboratory, Madison (1999).

Enviado: 01/09/05

Reenviado: 07/02/06

Aprovado:16/02/06 